\title{
Vulnerabilidade e violência: \\ uma nova concepção de risco para o estudo dos homicídios de jovens
}

Caren Ruotti ${ }^{1}$

Viviane Coutinho Massa ${ }^{2}$

Maria Fernanda Tourinho Peres ${ }^{3}$

RUOTTI, C.; MASSA, V.C.; PERES, M.F.T. Vulnerability and violence: a new conception of risk for the study of youth homicides. Interface - Comunic., Saude, Educ., v.15, n.37, p.377-89, abr./jun. 2011.

In Public Health, violence has been studied according to the classic risk approach. The analyses developed in such perspective are able to show population tendencies of morbidity and mortality, and also identify risk factors that are part of the causal chain of violence. Nevertheless, even though they are important as sources of information and hypotheses, when isolated such analyses are not capable of dealing with the complexity that is involved in violence. This paper aims at starting a reflection on the possibilities of the use of the vulnerability concept in the study of violence, specifically for understanding the situations that make youths be the main homicide victims. It is proposed a new approach to risk that considers the sociocultural processes that are present in the vulnerability of such group to lethal violence, through a perspective that presents the specificities of youth and the challenge imposed by the contemporary social life.

Keywords: Risk. Vulnerability. Homicides. Youth.
No campo da saúde pública, a violência tem sido estudada em consonância com a clássica abordagem de risco. Em geral, as análises desenvolvidas dentro desta perspectiva permitem evidenciar as tendências populacionais de morbimortalidade, além de identificarem fatores de risco relacionados na rede de causalidades. No entanto, embora importantes como fontes de informação e hipóteses, isoladas essas análises não são capazes de dar conta da complexidade envolvida no fenômeno.

Este artigo tem como objetivo iniciar uma reflexão sobre as possibilidades de uso do conceito de vulnerabilidade no estudo da violência, especificamente no entendimento das situações que tornam os jovens as principais vítimas de homicídios. Propõe-se, assim, uma nova concepção de risco que leva em consideração os processos sociais e culturais presentes na vulnerabilidade desse grupo à violência letal, por meio de uma perspectiva que apresente as especificidades inerentes à condição juvenil e aos desafios representados pela conformação social contemporânea.

Palavras-chave: Risco. Vulnerabilidade. Homicídios. Jovens.

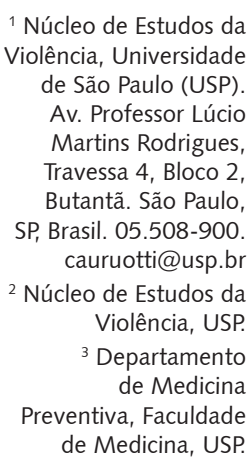

${ }^{1}$ Núcleo de Estudos da Violência, Universidade de São Paulo (USP) Av. Professor Lúcio Martins Rodrigues, Travessa 4, Bloco 2 Butantã. São Paulo, SP, Brasil. 05.508-900. cauruotti@usp.br ${ }_{2}^{2}$ Núcleo de Estudos da Violência, USP.

${ }^{3}$ Departamento de Medicina

Preventiva, Faculdade de Medicina, USP. 


\section{Introdução}

O impacto que a violência vem exercendo na morbimortalidade da população nas últimas décadas, alterando o perfil de problemas de saúde no Brasil e no mundo, transformou a violência em uma questão de saúde pública (Krug et al., 2002). Embora, em princípio, a violência, como fenômeno sócio-histórico, não seja objeto do campo da saúde pública e não constitua um problema médico típico (Minayo, Souza, 1997). Assim, as diversas consequências da violência para a integridade física, psicológica e emocional das pessoas, afetando sua qualidade de vida, somadas aos efeitos sobre a demanda nos serviços de saúde e aos altos custos sociais produzidos, acabam por legitimar a violência como uma preocupação no campo da saúde, não só no tratamento dos agravos, mas também na proposição e implantação de ações preventivas.

Entre as diferentes manifestações de violência, esse impacto é sentido sobremaneira no que diz respeito ao crescimento dos homicídios no país, em especial na população de 15 a 24 anos (Souza, Lima, 2006; Mello-Jorge, 1998; Minayo, 1990). Conforme dados do Ministério da Saúde (SIM/DATASUS), os homicídios aparecem como a primeira causa de morte entre os jovens já na década de 1990, ou seja, não só ocupam a primeira posição dentre as causas externas, mas ultrapassam todos os outros grupos de causas. Souza e Lima (2006), tendo como base o ano de 2003, mostram que os coeficientes de mortalidade por homicídios (/100 mil hab) chegam a 42,5 entre os adolescentes de 15 a 19 anos e a 70,0 na faixa de vinte a 24 anos, bastante superior à média nacional para a população total no mesmo período, da ordem de 28,9/100 mil hab. Ademais, o grupo mais exposto a este tipo de violência vem sendo, amplamente, o do sexo masculino. No Brasil, entre o período de 1999 a 2000, o risco de homens nessa faixa etária serem vítimas de homicídios foi quase 12 vezes maior que o de mulheres (Souza, 2005), o que aponta para diferenciais de gênero atuando na conformação dessas mortes. Observa-se, dessa maneira, não só uma sobremortalidade masculina por homicídios, mas diferenças significativas no que diz respeito ao local de ocorrência e aos fatores envolvidos nesses eventos. Os homicídios masculinos, por exemplo, prevalecem no espaço público (como ruas e bares) e estão, hoje, fortemente relacionados à criminalidade; já os homicídios femininos ocorrem, preferencialmente, no espaço privado, e estão mais relacionados a conflitos de ordem familiar (Schraiber, Gomes, Couto, 2005; Souza, 2005), sendo que, em ambos os casos, os agressores são predominantemente homens.

Os grandes centros urbanos foram os mais afetados por esta tendência, consolidando um caráter "endêmico" com um padrão desigual de distribuição das mortes por homicídios, como resultado de um conjunto de processos sociais que se tornam mais proeminentes nessas áreas, como as desigualdades nas condições de vida (Gawryszewski, Costa, 2005; Cardia, Adorno, Poleto, 2003; Barata, Ribeiro, 2000) e o estabelecimento de um mercado de atividades ilícitas e criminosas, sobretudo em torno do tráfico de armas e drogas (Zaluar, 2004, 1994). Um exemplo pode ser encontrado no município de São Paulo que, até início dos anos 2000, apresentou altas taxas de mortalidade por homicídio, em especial na população jovem, com grandes disparidades intraurbanas na distribuição do risco de morte (Gawryszewski, Costa, 2005) ${ }^{4}$. Verifica-se, desse modo, que, dentro dos próprios centros urbanos, as desigualdades perduram nas chances de um jovem ser vítima de homicídio, sendo maiores nas áreas que apresentam condições socioeconômicas desfavoráveis.

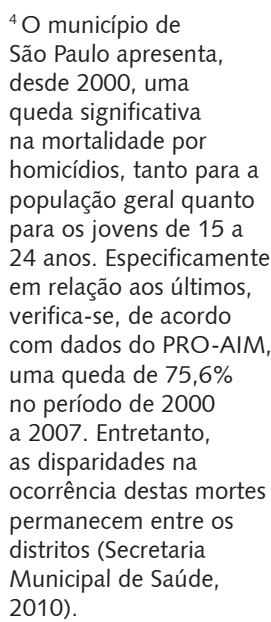


No campo da saúde pública, a violência tem sido estudada em consonância com a clássica abordagem de risco. De forma geral, as análises desenvolvidas dentro desta perspectiva permitem evidenciar as tendências populacionais de morbimortalidade por violência, como o peso da vitimização juvenil por homicídio, além de identificar fatores de risco relacionados na rede de causalidades. No entanto, embora importantes como fontes de informação e hipóteses (Ayres et al., 2003), isoladas essas análises não são capazes de dar conta da complexidade envolvida no fenômeno da violência.

É diante dos limites apresentados pelas análises de risco que o conceito de vulnerabilidade vem se constituindo em um referencial importante, sobretudo a partir de estudos desenvolvidos no campo do HIV/AIDS. A adoção desse conceito assinala para alterações tanto no nível epistemológico como na esfera das práticas em saúde, nomeadamente no que diz respeito à prevenção de agravos (Sanchez, Bertolozzi, 2007; Ayres et al., 2003; Buchalla, Paiva, 2002; Delor, Hubert, 2000).

A abordagem da vulnerabilidade tem como contribuição fundamental lançar luz sobre a dinâmica dos processos sociais, culturais e individuais que conformam a suscetibilidade dos indivíduos a um determinado evento, proporcionando uma reflexão mais abrangente sobre os processos saúde-doença. Permite considerar, assim, tanto as suscetibilidades orgânicas, como a "forma de estruturação de programas de saúde, passando por aspectos comportamentais, culturais, econômicos e políticos" (Ayres et al., 2003, p.20). Desta maneira, o seu potencial analítico e prático favorece o estabelecimento de um conhecimento interdisciplinar no campo da saúde pública e estimula sua aplicabilidade na análise de diferentes objetos de interesse (Ayres et al., 2003), como no caso particular da violência (Peres, 2007; Paulilo, Bello, 2002).

Nesse contexto, este artigo tem como objetivo iniciar uma reflexão sobre o conceito de vulnerabilidade e as possibilidades de seu uso no estudo da violência, especificamente no entendimento das situações que tornam os jovens atualmente as principais vítimas de homicídios. Pretende-se, assim, levar em consideração os processos sociais e culturais presentes na vulnerabilidade desse grupo à violência letal, por meio de uma perspectiva que apresente as especificidades inerentes à condição juvenil e os desafios representados pela conformação social contemporânea. Trata-se de aproveitar a importância heurística da vulnerabilidade, que tem apresentado relevância no campo do HIV/AIDS, para entender a complexidade dos processos envolvidos na problemática da violência e auxiliar na definição de medidas de prevenção. Isso não significa uma transposição direta de questões colocadas pela epidemia de AIDS para o estudo da violência, já que esta não é um agravo com agente etiológico específico, e sim um fenômeno cujas causas são múltiplas e atuam em complexa e dinâmica relação (Peres, 2007; Minayo, 1990). Contudo, os avanços nos estudos sobre HIV/AIDS, que se refletem no conceito de vulnerabilidade, ao apontarem a necessidade de se considerarem as condições estruturais de vida e os valores e normas culturais que atuam na conformação da epidemia, permitem uma aproximação profícua com o estudo da violência.

\section{O risco epidemiológico e a vulnerabilidade}

O conceito de risco, central nos estudos epidemiológicos, expressa a probabilidade de ocorrência de doenças e agravos à saúde de populações em determinadas situações ou contextos (Ayres et al., 2003; Almeida Filho, 1992). As análises epidemiológicas de risco permitem estabelecer associações probabilísticas de distribuição populacional de um determinado agravo entre diferentes condições objetivas, mensuráveis, como idade, sexo, renda, etc., apresentando caráter eminentemente quantitativo e populacional. Trata-se, neste sentido, de uma categoria abstrata e analítica que pressupõe certa relação de dependência entre um fator de exposição (fator de risco) e um efeito à saúde, segundo o modelo de raciocínio causal. A identificação de fatores de risco a um determinado agravo constitui, assim, um eixo fundamental das análises que sustentam as práticas preventivas em saúde.

Como indica Czeresnia (2004), os modelos de análises de risco, ao terem como critério a experimentação, exigem o controle de todos os fatores que podem interferir na experiência, a fim de que sejam criadas as condições que permitam observar uma relação de causa e efeito. Entretanto, como indica a autora, a construção desses modelos estabelece um "processo de purificação" que cria uma abstração do fenômeno estudado e, por consequência, reduz a sua complexidade. Segundo 
Castel (1986), esse processo promove a dissolução do sujeito ou do indivíduo concreto (alvo das medidas preventivas), o qual é substituído por um conjunto de fatores de risco.

Os estudos voltados para o HIV/AIDS, em especial aqueles realizados no início da epidemia, são um exemplo da adoção do modelo de risco e de suas consequências para as práticas preventivas. Um dos grandes problemas ocasionados por esta abordagem, já no início dos anos 1980, foi a estigmatização de certos grupos identificados como grupos de risco.

Cabe ressaltar que este processo de estigmatização, evidenciado nos clássicos quatro H's (homossexuais, hemofílicos, heroinômanos e haitianos), estruturou-se, de acordo com Ayres et al. (2003), a partir da transformação sofrida pelo conceito de risco, que passou de uma categoria analítica de inferência causal (e, portanto, eminentemente abstrata e coletiva), para uma categoria operacional de caráter individualizante - que se fazia reconhecer pela presença de características que marcavam a pertinência de sujeitos a determinados "grupos de risco", alvo privilegiado das ações preventivas. Desta forma, o conceito de risco passa a demarcar fronteiras identitárias e apoiar a proposição de medidas de isolamento e abstinência sexual (Ayres et al., 2003; Delor, Hubert, 2000). Neste sentido, o risco passa a operar como uma categoria ontológica, como uma marca identitária do sujeito que, em si, representa o risco que virtualmente porta (Ayres et al., 2003).

Com a identificação do HIV como agente viral causal, inicia-se um segundo estágio, no qual o risco é associado não mais a grupos específicos, mas a práticas relacionadas à transmissão do vírus. Nesse estágio começam a surgir práticas centradas na categoria comportamento de risco e em estratégias de educação/informação em saúde (Ayres et al., 2003). Por conseguinte, os comportamentos individuais passam a ser o foco das campanhas preventivas e o indivíduo passa a ser responsabilizado pela sua eventual contaminação. Embora esse estágio represente um avanço em relação ao anterior, retirando o estigma de certos grupos e universalizando a preocupação com a doença, acaba por reforçar o modelo de indivíduo racional, cujos comportamentos poderiam ser modificados por meio de campanhas preventivas, além de reforçar a ideia de que cada indivíduo, uma vez dotado de informações necessárias, é responsável pela sua proteção.

Um terceiro estágio surge diante dos limites das estratégias de prevenção baseadas nas categorias de grupo e comportamento de risco e da constatação de que a contaminação pelo vírus permanecia crescente e atingia, com maior intensidade, áreas com condições socioeconômicas precárias e setores mais enfraquecidos da sociedade (como jovens, mulheres, negros). Evidencia-se, desta maneira, tanto o caráter não homogêneo da exposição ao vírus na população em geral como o fato de que a mudança de práticas e comportamentos mantém relação com diferentes fatores situados além da vontade individual (Ayres et al., 2003).

É nesse momento que começa a se delinear uma nova proposta preocupada em entender as condições do contexto que compõem as diferentes suscetibilidades à doença. Conforma-se, assim, uma passagem do risco individual para o entendimento da vulnerabilidade, que, segundo Ayres et al. (2003, p.123), refere-se ao:

[...] movimento de considerar a chance de exposição das pessoas ao adoecimento como a resultante de um conjunto de aspectos não apenas individuais, mas também coletivos, contextuais, que acarretam maior suscetibilidade à infecção e ao adoecimento e, de modo inseparável, maior ou menor disponibilidade de recursos de todas as ordens para se proteger de ambos.

As análises de vulnerabilidade, portanto, buscam resgatar a complexidade dos processos saúdedoença ao incorporarem os diferentes fatores envolvidos e as mútuas interferências (Ayres et al., 2003). Nesse sentido, ao contrário da categoria "grupo de risco", o conceito de vulnerabilidade não fixa identidades grupais, já que procura apreender as diferenças na suscetibilidade ao vírus enquanto efeito de relações sociais específicas que dizem respeito ao corpo social como um todo (Ayres et al., 2003). A vulnerabilidade não é assim um estado, uma característica essencial dos indivíduos, mas uma situação. Apresenta uma natureza potencialmente instável, que pode se alterar em função do tempo, das relações ou de características do contexto social mais amplo (Delor, Hubert, 2000). A 
partir de análises de vulnerabilidade, ênfase é dada a programas de intervenção que objetivam o "empoderamento" em face da epidemia.

A abordagem da vulnerabilidade é caracteristicamente interdisciplinar e fortemente ancorada nas Ciências Sociais e Humanas, buscando compreender, para além dos determinantes epidemiológicos, a dimensão dos sentidos e dos significados da exposição dos sujeitos a determinadas situações de risco, bem como as implicações e os efeitos diferenciados dessas exposições nas trajetórias individuais e interativas.

Delor e Hubert (2000) destacam três níveis de inteligibilidade para o entendimento do conceito de vulnerabilidade: o nível da trajetória social, o nível em que duas trajetórias se cruzam, e o contexto social, sendo a construção da identidade o processo de síntese onde estas três dimensões devem ser situadas. O primeiro nível diz respeito à posição no curso da vida, que pode ser compartilhada por diferentes indivíduos, tornando-se essencial para se entender a adoção de certos comportamentos. O segundo enfatiza a dimensão da interação entre os indivíduos e os elementos aí implicados, como as diferenças de status e poder, que influenciam diretamente as possibilidades frente ao risco. Já o nível do contexto social envolve as configurações sociais e normas culturais que atuam diretamente nas formas e interesses que regem o encontro de duas trajetórias. Para os autores, a construção de identidade é entendida como um processo que se destina a manter, expandir ou proteger o espaço de vida em que o sujeito é socialmente reconhecido, sendo que a confrontação com diferentes riscos requer a constante construção e reelaboração desse processo, por meio da qual o sujeito empenha-se em produzir uma (sempre temporária) síntese desses três níveis.

Ainda segundo os autores, para se entender as situações de vulnerabilidade, é necessário apreender as conexões existentes entre as noções de risco (enquanto evento adverso ou potencialmente hostil), identidade e vulnerabilidade. Assim, uma vez que o processo de identidade não é algo estático, e sim uma constante, ou seja, um trabalho de síntese por meio do qual o indivíduo lida com diferentes riscos da vida diária, as situações de vulnerabilidades seriam "as circunstâncias - em termos de momentos e lugares específicos - durante as quais este exercício vital é mais dolorido, difícil ou perigoso" (Delor, Hubert, 2000, p.1560, tradução nossa). A vulnerabilidade teria, assim, um lado "externo", representado pelas tensões e hostilidades que atingem indivíduos ou grupos, e um lado "interno", que se refere à fragilidade em lidar com essas dificuldades (Chambers apud Delor, Hubert, 2000). Disso decorre a distinção entre exposição, capacidade e potencialidade no espaço de vulnerabilidade, ou seja, as possibilidades de exposição do sujeito a situações de crise (exposição), os recursos que o sujeito tem para enfrentar estas situações (capacidade), e, por fim, as consequências desta exposição (potencialidade) (Watts, Bolhe apud Delor, Hubert, 2000). Ressaltase, assim, a forma diferencial com que as pessoas vivenciam a exposição a um determinado agravo, sendo que um mesmo indivíduo não tem a mesma vulnerabilidade em diferentes contextos, em diferentes relações e em diferentes pontos de sua trajetória.

Dessa maneira, o quadro de vulnerabilidade permite compreender as formas pelas quais os indivíduos enfrentam os eventos adversos e adotam certos comportamentos, não de acordo com a visão de um sujeito racional que orienta sua ação apenas pela disponibilidade de informações, mas sob a perspectiva de um sujeito imbricado em um sistema dinâmico de relações e constrangimentos de diferentes ordens (sociais, políticos e econômicos), que influi nas suas escolhas e condições de existência.

\section{Violência, risco e vulnerabilidade}

No campo da saúde pública, a centralidade do paradigma do risco no estudo da violência está consolidada no Relatório Mundial sobre Violência e Saúde (Krug et al., 2002). Desta maneira, procuram-se identificar os fatores de risco para as diferentes manifestações de violência, assim como conhecer os mecanismos causais e reconhecer os grupos particularmente expostos, a fim de se estabelecerem ações preventivas. Contudo, as análises epidemiológicas de risco neste campo, ao fragmentarem um fenômeno complexo como a violência, também apresentam suas limitações. 
Desse modo, conquanto as análises de risco mantenham-se importantes para identificar as diferenças nas distribuições populacionais dos agravos, elas não conseguem apreender os significados concretos das vivências dos indivíduos frente às distintas situações de exposição. Além disso, como exemplificado no caso da epidemia de HIV/AIDS, quando o risco de categoria abstrata é operacionalizado para as práticas preventivas, sem as mediações necessárias, acaba por estigmatizar grupos populacionais, o que não raro acontece quando se trata da violência.

É visível, a partir da década de 1980, com o aumento das taxas de mortalidade por homicídio, uma vasta produção acadêmica sobre o tema, descrevendo as curvas de crescimento, a distribuição das mortes no território nacional, incluindo a identificação de grupos populacionais com maior risco de morte por homicídio (Mello-Jorge, 1998; Minayo, 1990). Estes estudos demonstram que as populações de regiões periféricas, especialmente os jovens, constituem o mais claro grupo de risco para vitimização fatal.

No entanto, a identificação de certas populações e locais mais vitimizados acaba por produzir os efeitos negativos acima mencionados. Segundo Peres (2007), assim como na epidemia de HIV/AIDS, no caso dos homicídios, aqueles que compõem os "grupos de risco" para vitimização fatal - jovens, negros, moradores de áreas periféricas - acabam por representar, para determinados seguimentos da sociedade, uma ameaça potencial, enquanto membros das "classes perigosas". É visível, aqui, a cisão da população entre dois grupos - os indivíduos perigosos e os indivíduos a serem protegidos e a criação de barreiras urbanas para se evitar o contato e "garantir" a proteção. Tais barreiras são visualizadas nas fortificações urbanas - muros altos, grades nas janelas -, nos veículos blindados e nos vidros fechados dos carros nas ruas (Caldeira, 2000). A intensificação do sentimento de insegurança e forte tendência a segregação urbana, aliados à inoperância dos agentes de segurança pública, geram, ainda, demandas por serviços de segurança privados e por ações extralegais de "justiça".

Peralva (2000) aponta algumas situações onde é sensível a estigmatização de jovens provenientes de áreas periféricas, especialmente quando estes procuram acesso a empregos ou cursos em áreas mais centrais. Ademais, a violência e a corrupção policial são outros aspectos fortemente presentes no dia a dia das populações caracterizadas como "grupos de risco", sendo mais uma forma de estigmatização destas populações por parte da ação policial. Em um estudo realizado em uma comunidade pobre do Rio de Janeiro, Zaluar (1994) também apresenta algumas reflexões sobre a criminalização dos pobres ao colocar que recai sobre estes os efeitos perversos da crise econômica e do desemprego, além do estigma de criminoso e as ações de repressão, exercidas, sobretudo, pela polícia, que utiliza indistintamente um tratamento violento.

Com o objetivo de enfrentar o problema da violência e criminalidade urbanas, começam a surgir, mais recentemente, guias e manuais que incentivam o maior engajamento do indivíduo com a sua segurança, seguindo o modelo de ação centrado no comportamento de risco e nas estratégias de educação e informação. Estes materiais ensinam como evitar situações de violência, com a adoção de comportamentos seguros e defensivos no trânsito, nas ruas e nos bares. Essas informações são veiculadas, sobretudo, pelos meios de comunicação, para que possamos reconhecer possíveis suspeitos - com base no perfil de risco -, evitar situações de maior exposição, nos comportar corretamente em situações violentas, evitando, assim, um desfecho fatal (Peres, 2007). Com posse das informações, cabe, a cada um de nós, zelar pela nossa proteção, mudando o nosso comportamento.

As questões acima levantadas e a experiência acumulada no campo do HIV/AIDS tornam evidente a necessidade de uma abordagem ao fenômeno da violência que supere os limites inerentes à abordagem centrada no risco, permitindo entender a própria estigmatização social que recai sobre determinados jovens e os diferentes efeitos que isso pode proporcionar, além de outras situações que podem aproximá-los de desfechos violentos. As análises de vulnerabilidade, ao considerarem tanto os perigos ou eventos hostis que podem afetar os indivíduos quanto a fragilidade destes em enfrentá-los (Chambers apud Delor, Hubert, 2000), podem auxiliar na compreensão desses processos culturais e sociais envolvidos nas situações de violência, bem como das diferentes formas de os jovens lidarem com estas situações, e o sentido por eles atribuídos.

Assim, um dos desafios suscitados pelo estudo da vulnerabilidade dos jovens aos homicídios na atualidade é entender os significados da exposição (voluntária ou involuntária) às situações arriscadas 
ou de "risco" - como o engajamento em alguma atividade ilícita -, que os aproximam da possibilidade de morrerem de forma violenta. Esta indagação situa-se sobre o pano de fundo de processos sociais em curso que alteram os contornos da socialização das novas gerações, implicando diferentes consequências na construção de suas trajetórias de vida. Entre esses processos, tem-se a própria configuração do risco como categoria central na sociedade contemporânea, colocando em discussão as transformações que incidem sobre os elementos constitutivos da modernidade.

\section{Contexto: risco e modernidade}

É preciso destacar, primeiramente, a pluralidade que a palavra risco adquire nos seus usos e sentidos nas diversas sociedades no decorrer da história (Ayres, 1995) e mesmo atualmente, dependendo da área de estudo na qual é empregada e de acordo com as diferentes correntes interpretativas (Lupton, 1999). Porém, na modernidade, como salienta Giddens (2002), o movimento de abandono das formas tradicionais de fazer as coisas produz uma nova forma de lidar com o futuro, instaurando o risco como conceito central, cujo sentido diz respeito à possibilidade de prever probabilisticamente os acontecimentos futuros (cálculo de riscos) e de agir de forma colonizadora em relação a este futuro, mesmo considerando a imprevisibilidade que lhe é intrínseca.

De acordo com La Mendola (2005), a interpretação moderna do risco pretende afirmar que os princípios do racionalismo individualista e utilitarista devem guiar as condutas dos agentes, sustentando, desse modo, que os perigos devem ser enfrentados de forma individual e responsabilizando os agentes individualmente pelas consequências. O risco epidemiológico é um dos frutos dessa lógica, a qual é fortemente racionalizadora (com base no conhecimento científico) e estritamente relacionada ao processo de individualização na modernidade reflexiva (Beck, 1997). Por individualização compreende-se o processo que transfere, para o indivíduo, a responsabilidade pela construção de suas trajetórias e pelas consequências de seus possíveis fracassos, assim,

as oportunidades, ameaças, ambivalências da biografia, que anteriormente era possível superar em um grupo familiar, na comunidade da aldeia ou se recorrendo a uma classe ou grupo social, devem ser cada vez mais percebidas, interpretadas e resolvidas pelos próprios indivíduos.

(Beck, 1997, p.18)

Esse processo de individualização ocorre num contexto no qual as referências sociais dominantes instauradas pela sociedade industrial sofrem de exaustão, desintegração e desencantamento, o que impõe, aos indivíduos, todo esforço na definição de novas significações (Beck, 1997). Como indica Giddens (2002), a modernidade tem como principais dimensões: o estabelecimento de um "mundo industrializado", o desenvolvimento do capitalismo, bem como a formação dos Estados-nação. $\mathrm{Na}$ contemporaneidade, estaríamos na presença de uma radicalização dessa modernidade, ou seja, num outro estágio dessa modernização definida por Beck (1997) como "modernidade reflexiva", na qual o progresso pode se transformar em autodestruição. Isto porque os riscos produzidos pela própria modernidade parecem escapar do controle, inclusive quando se observa a produção dos riscos de alto alcance ou riscos globais (como os riscos ambientais), como consequência do próprio desenvolvimento tecnológico. Além disso, verificam-se mudanças estruturais, inclusive no que se refere à esfera do trabalho, sendo que algumas das fontes de significação cultural da modernidade apresentam-se em decomposição (como a própria fé no progresso). A incerteza torna-se, portanto, experiência fundamental da contemporaneidade.

Assim sendo, como explicita Le Breton (2000), a modernidade provoca descontinuidades de sentido e confusão nas referências socialmente instituídas, conduzindo cada indivíduo à necessidade de se autorreferenciar, ou seja, ao imperativo de "buscar em si mesmo, dentro dos seus próprios recursos, aquilo que ele encontrava antes no interior da cultura e na companhia dos outros" (Le Breton, 2000, p.12, tradução nossa). Segundo o autor, é dentro desse processo que a significação antropológica e social sobre as tomadas ou práticas de risco pelas pessoas em geral, e especialmente pelos jovens, deve ser buscada. Destaca-se, por conseguinte, outra maneira de se conceber o risco, 
essencial na análise da vulnerabilidade à violência, que "considera o risco como sendo o fruto instável de um processo de construção pelos indivíduos e coletividades" (Delor, Hubert, 1997, p.21), indo além da abordagem técnica do risco da qual o risco epidemiológico é resultado.

\section{Jovens e situações de vulnerabilidade}

É possível supor que a vulnerabilidade dos jovens à violência relaciona-se, atualmente, às conformações gerais da "modernidade reflexiva" (nos termos de Beck, 1997) e, portanto, às consequências que este processo traz para a trajetória individual dos sujeitos. De um lado, porque obriga o sujeito a tomar decisões de forma solitária e a responsabilizar-se pelos resultados de suas "escolhas" (as quais não estão livres de constrangimentos, uma vez que mediadas pelos processos sociais em curso), o que, embora proporcione certa margem de liberdade ao sujeito, ao abrir novas possibilidades, impõe o árduo peso de uma responsabilização individual. Nesse contexto, o controle dos riscos passa cada vez por estratégias individuais, já que, socialmente, há uma maior isenção em relação à responsabilidade coletiva de gestão dos riscos, jogando para os indivíduos o ônus pelos possíveis efeitos negativos (Mitjavila, Jesus, 2004; Peralva, 2000). De outro lado, porque desfaz os limites simbólicos capazes de dar suporte a um sentimento de identidade - e é na busca desses limites que muitos jovens acabam por lançar-se em situações de risco, onde a confrontação com a morte (de forma imaginária ou real) pode tornar-se elemento fundamental na afirmação do valor de sua existência (Le Breton, 2000).

Assim, segundo Le Breton (2000), a transição para a vida adulta representa, na modernidade, um momento crítico onde essas condutas de risco tornam-se emblemáticas e fortemente adotadas. Diante da indeterminação social instaurada pela modernidade, não há mais ritos de passagem que possam simbolizar e legitimar a entrada na vida adulta e, sobretudo, referenciar o futuro e remover a incerteza sobre a condução da existência, a exemplo das sociedades tradicionais. Esta simbolização da passagem fica a encargo dos próprios jovens que precisam encontrar uma resposta a suas expectativas. E é nesse momento que as condutas de risco ganham um valor essencial, na forma de um rito, por meio do qual os jovens buscam achar um sentido que justifique suas vidas.

Nesse sentido, esses comportamentos arriscados, muitas vezes auto ou heterodestrutivos, não devem ser interpretados como uma fuga, uma irresponsabilidade dos indivíduos. Pelo contrário, esses comportamentos, mesmo os mais aparentemente irresponsáveis, indicam uma demanda implícita por responsabilidade (La Mendola, 2005) e, portanto, demonstram a busca por um sentimento de identidade (Le Breton, 2000). Desse modo, diante da ausência de limites simbólicos que sirvam de orientação, é na experiência essencialmente corporal que esse sentimento é buscado, por isso, o risco - e, mesmo, o risco de morte - adquire importância nesse processo. Vencer a morte solicitada por meio de práticas de risco significa que a existência individual tem um valor (Le Breton, 2000).

De acordo com La Mendola (2005), os significados dos comportamentos de risco, inclusive os mais destrutivos, relacionam-se também à desconfiança em relação aos mecanismos sociais de distribuição de sucesso. A modernidade, ao fazer do risco a forma exclusiva de persecução de fins na sociedade contemporânea, estabelece, como mensagem fundamental, que aqueles que se empenham necessariamente obterão sucesso. Contudo, essa fórmula acaba não se confirmando na realidade, uma vez que a obtenção de sucesso submete-se a regras sociais de reconhecimento que escapam constantemente aos critérios racionais de seleção dos melhores.

Lança-se, assim, aos indivíduos, a necessidade de adotarem atitudes de risco, para aquisição de sucesso sem, contudo, enfatizar o elemento que lhe é complementar, ou seja, a segurança, abrindo margem para comportamentos destrutivos. Ressalta-se, portanto, a existência de um sistema social que legitima o risco, inclusive na esfera do trabalho (Sennet, 2005), ocultando a necessidade das redes de proteção para prevenir os efeitos negativos que podem conter a ação de arriscar-se, especialmente na fase da juventude, caracterizada como um momento de forte indeterminação social e identitária.

Ademais, soma-se a esse processo geral, que atinge a juventude como um todo, a existência de diferenças profundas na vivência dessa fase de acordo com a posição social desses jovens, inclusive quando consideramos a exposição à violência. Assim, embora os desafios sejam semelhantes, os 
contextos e os recursos disponíveis no seu enfrentamento não são os mesmos, abrindo espaço para diferentes situações de vulnerabilidade.

Como define Pais (2005), a situação social dos jovens na modernidade é caracterizada, cada vez mais, pela imprevisibilidade. As novas conformações sociais marcadas por tendências globalizantes, avanço tecnológico e mutações do trabalho (Telles, 2006; Sennet, 2005; Giddens, 2002)

transformam o futuro em algo indefinido e arriscado, lançando desafios para a sociedade em geral e, especialmente, para as novas gerações. Nesse sentido, surge, como problema crucial, o processo de transição para a vida adulta e as possibilidades de os jovens conseguirem lograr sua inserção social. Embora esse problema atinja todos os jovens, as desigualdades econômicas e sociais, por certo, imprimem diferenciações importantes nos recursos existentes e nas formas possíveis de se alcançar essa inserção.

Segundo Telles (2006), são as novas gerações que colocam em evidência os pontos nevrálgicos das novas configurações sociais. De um lado, os jovens já entram num mundo social marcado pelo trabalho precário e o desemprego, em tempos de dissolução do capitalismo fordista e surgimento do capitalismo flexível (Sennet, 2005). Por outro, vivenciam uma experiência, inimaginável para gerações anteriores, dos capitais globalizados que fazem expandir os circuitos do consumo de bens materiais e simbólicos para além das fronteiras das grandes nações, atingindo os mercados populares. E é no centro dessa nova realidade, a qual redefine novas dinâmicas locais, novas redes sociais, novas sociabilidades, que os mais jovens acabam traçando seus percursos, cada vez mais instáveis e precários (Telles, 2006).

As trajetórias dos jovens tornam-se, nesse contexto, trajetórias não lineares, já que sujeitas a diferentes contingências, imprevistos, incertezas (Pais, 2005), cuja característica principal é a retomada de caminhos já percorridos. As incertezas que compõem essas trajetórias gravitam com intensidade na esfera do trabalho. A flexibilização que caracteriza o capitalismo na modernidade faz com que a experiência dos jovens, no mundo do trabalho, não se dê a partir de uma rotina estável ou de uma carreira previsível, e estes acabam por inventar diferentes formas de ganhar dinheiro ou de "ganhar a vida". Ainda de acordo com Pais (2005), essa flexibilização do trabalho, que atinge a todos, acaba sendo vivida pelos jovens como aventura ou, mesmo, desventura. Isto porque, para alguns, essa flexibilidade acaba por representar viver na precariedade, com todos os aspectos negativos que advêm dessa situação; para outros, essa flexibilidade representa a abertura de novas oportunidades, a possibilidade de trajetórias sociais ascendentes. Entretanto, é a incerteza e a improvisação que pautam seus percursos. É nesse sentido que conseguir um emprego, muitas vezes, é tido como um lance de sorte e a própria vida passa a ser vivida nos moldes de um jogo, onde a necessidade de astúcia e os elementos de aleatoriedade e sorte tornam-se centrais.

De acordo com Sennet (2005), o capitalismo flexível institui o risco como algo necessário. Esse é um tempo, portanto, que valoriza o desempenho, a performance e o sucesso. Correr riscos, tentar a sorte torna-se uma necessidade diária para todos, e essa atitude acaba por ser valorizada: "A moderna cultura do risco é peculiar naquilo que não se mexer é tomado como sinal de fracasso, parecendo a estabilidade quase uma morte em vida. O destino, portanto, conta menos que o ato de partir" (Sennet, 2005, p.102). O risco, nessa cultura, passa a ser um teste de caráter, é preciso correr risco mesmo que, racionalmente, se saiba que é possível fracassar. Especificamente para os jovens, sua situação limiar acaba por torná-los mais flexíveis, inclusive em termos de assumirem riscos. Contudo, como indica Pais (2005), a propensão a assumir riscos e jogar com a própria vida seria mais forte entre os sujeitos em que a própria vida apresenta-se mais cheia de indeterminações. Assim, no jogo da vida, muitos jovens seriam levados a desafiarem o próprio destino, como no caso de jovens inseridos em trajetórias de exclusão social. Desse modo, os recursos que os jovens possuem (títulos escolares, redes de conhecimento e, também, astúcia) variam como variam as formas inventadas pelos jovens, a partir desses recursos ou na sua ausência, no empenho de ganhar a vida.

Telles (2006), que reconstruiu a trajetória de jovens moradores na periferia do município de São Paulo, também mostra as diferentes estratégias e recursos de que os jovens lançam mão na tentativa de participarem do mercado de trabalho. Os percursos traçados demonstram, da mesma forma, a precariedade e instabilidade que marcam suas experiências e evidenciam novos padrões 
de desigualdades que questionam as formas tradicionais de pensar o social. Segundo a autora, o cruzamento entre a precarização do emprego e os circuitos globalizados conforma um mundo social que não pode ser entendido nos termos de uma sociedade dualizada, que contraponha, de um lado, "exclusão social" e, de outro, a "cidade global". Os jovens, inclusive das áreas periféricas, transitam por esses circuitos globalizados, que funcionam como polos de gravitação, onde a própria experiência do trabalho precário se realiza.

Ainda de acordo com Telles, isso não significa que estamos diante de uma sociedade onde se estabelece uma democratização da sociedade do consumo. As desigualdades são inerentes ao capitalismo contemporâneo, perpassando todo o campo social. O que está suposto, entretanto, são novas configurações sociais onde as atuais formas excludentes de emprego se conjugam à expansão desses circuitos de consumo de bens materiais e simbólicos, conformando diferentes maneiras de "ganhar a vida" e diferentes estratégias de participação, inclusive entre os mais pobres. Destaca-se, nesse sentido, o endividamento na compra desses bens e a inserção em atividades que podem beirar a informalidade ou, mesmo, a ilegalidade. A própria expansão do mercado organizado do tráfico de drogas está diretamente conectada a essa economia globalizada, capturando, entre os mais os jovens, grande parcela dos seus membros, inclusive pela via de atração que constitui o uso de drogas (Zaluar, 1994).

A criminalidade, fortemente atrelada a essa expansão do tráfico de drogas, tem se apresentado cada dia mais presente nas periferias e favelas, inclusive a partir da década de 1990, tornando-se parte das "opções" e "escolhas"5 apresentadas aos moradores desses locais. Configura-se, assim, como um aspecto de vulnerabilidade para muitos jovens, embora apenas uma minoria aceda às atividades criminais (Feltran, 2007; Peralva, 2000). Em presença das inúmeras dificuldades encontradas pelas pessoas, especialmente pelos jovens, ao tentarem uma inserção no mercado de trabalho, a "escolha" por esta "opção", apesar de se colocar, por um lado, como uma forma de acesso - a bens de consumo, a renda, a ampliação do status individual no grupo - também se insere em um contexto de risco de morte onipresente, ou seja, num contexto marcado pela violência resultante tanto da instituição policial como da comercialização ilegal de drogas (Feltran, 2007; Peralva, 2000).

As estratégias de resposta a este risco de morte podem ser variadas, desde a tentativa de contorná-lo até o engajamento no próprio narcotráfico. Isso revela uma dinâmica que vai além de aspirações a uma mobilidade social desviante, compreendendo diferentes sentidos de existência e alternativas de vida para melhor lidar com a experiência do risco, diante da falta de padrões estáveis de organização familiar, social e política, incluindo a ausência de ordem pública legítima (Feltran, 2007; Peralva, 2000). É nesse sentido que Peralva (2000) explicita que as condutas de risco dos jovens perante essas condições estão estritamente relacionadas à familiaridade com o risco de morte:

[...] isso fez com que se desenvolvesse no seio da juventude, e mais particularmente da juventude pobre (posto que para ela a cota de riscos associados à violência é mais elevada), o sentimento de que as condutas de risco talvez constituíssem, elas próprias, uma modalidade eficaz de resposta ao risco. Tratar-se-ia de antecipar o risco, de se apropriar dele, para melhor subjugá-lo. (Peralva, 2000, p.127)

Assim, a perda de confiança em mecanismos sociais que negam promessas feitas por meio da ambivalência e ambiguidade das mensagens, a violência

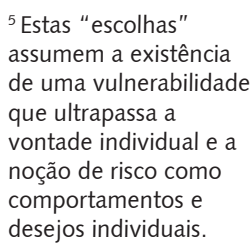


perpetrada por policiais e traficantes, bem como a falta de acesso a direitos são aspectos fortemente relacionados à entrada de muitos jovens no tráfico de drogas ou em outras práticas de risco (La Mendola, 2005; Peralva, 2000).

\section{Considerações finais}

Embora para alguns jovens os riscos ofereçam oportunidades e sejam aceitos na expectativa de benefícios [...] para muitos outros jovens a vida é como uma loteria, onde os riscos estão fora do controle e a segurança é uma questão de sorte. (Pais, 2005, p.55)

Ser jovem, mais do que ter biologicamente uma determina idade, significa pertencer a um mesmo grupo etário ou a uma mesma geração que compartilha uma situação social comum no processo histórico e social (Mannheim, 1982). Esse pertencimento específico, pautado pela cronologização da vida, altera o tipo de herança cultural, bem como a forma de pensar e viver os diferentes desafios impostos pelas mudanças sociais.

Assim, as novas gerações vivem, de uma forma específica, os processos engendrados pela modernidade atual. Os desafios impostos, como a precarização do emprego e a necessidade de arriscar-se, embora atinjam a todos, para os jovens adquirem uma dimensão mais acentuada. Isto porque ser jovem também significa um período no qual o processo de construção de identidade mostra-se nuclear, o qual se realiza, contudo, a partir de uma pluralidade de realidades e, muitas vezes, sem uma rede de apoio disponível que sirva de suporte (La Mendola, 2005).

Nesse sentido, apenas nascer numa mesma época não compreende vivenciar as mesmas experiências. Os fatores sociais e culturais atuantes conformam-se de maneiras particulares de acordo com a posição social ocupada por esses jovens, o que influencia diretamente na formação de suas trajetórias e, consequentemente, nas situações de vulnerabilidade à violência. De tal modo, essas situações vêm-se agravadas em contextos específicos, nos quais as condições socioeconômicas são restritas, a falta de acesso a direitos persiste devido à inoperância do Estado e a violência, tanto policial quanto dos grupos ligados ao tráfico de drogas, está intensamente presente. Delineia-se uma conjuntura onde as condutas de risco adquirem um terreno propício e os desfechos fatais para as trajetórias de muitos jovens acabam por compor a triste história de muitas famílias.

Torna-se, portanto, pertinente o uso do conceito de vulnerabilidade para a compreensão da violência envolvendo jovens, possibilitando, assim, considerar a multicausalidade que envolve este fenômeno e os diversos significados e sentidos que são atribuídos à exposição ao risco, os quais devem ser entendidos em conexão com as configurações sociais e culturais que permeiam o processo de individualização na modernidade reflexiva.

\section{Agradecimentos}

Este projeto foi desenvolvido sob coordenação de Maria Fernanda Tourinho Peres, como parte do programa CEPID-FAPESP, do Núcleo de Estudos da Violência da USP (Processo 98/14262).

\section{Colaboradores}

Os autores trabalharam juntos em todas as etapas de produção do manuscrito. 


\section{Referências}

ALMEIDA-FILHO, N. A clínica e a epidemiologia. Salvador: Apce/Abrasco, 1992.

AYRES, J.R.C.M. Ação comunicativa e conhecimento cientifico em epidemiologia: origens e significados do conceito de risco. 1995. Tese (Doutorado) - Faculdade de Medicina, Universidade de São Paulo, São Paulo. 1995.

AYRES, J.R.C.M. et al. O conceito de vulnerabilidade e as práticas de saúde: novas perspectivas e desafios. In: CZERESNIA, D.; FREITAS, C.M. (Orgs.). Promoção da saúde: conceitos, reflexões, tendências. Rio de Janeiro: Fiocruz, 2003. p.116-39.

BARATA, R.B.; RIBEIRO, M.C.S.A. Relação entre homicídios e indicadores econômicos em São Paulo, Brasil, 1996. Rev. Panam. Salud Publica, v.7, n.2, p.118-24, 2000.

BECK, U. A reinvenção da política: rumo a uma teoria da modernização reflexiva. In: BECK, U.; GIDDENS, A.; LASH, S. (Orgs.). Modernização reflexiva. São Paulo: Ed. Unesp, 1997. p.11-71.

BRASIL. Ministério da Saúde. SIM/DATASUS: informações de saúde. Disponível em: <http://www.datasus.gov.br>. Acesso em: 6 jan. 2010.

BUCHALLA, C.M.; PAIVA, V. Da compreensão da vulnerabilidade social ao enfoque multidisciplinar. Rev. Saude Publica, v.36, n.4, p.117-9, 2002.

CALDEIRA, T.P.R. Cidade de muros: crime, segregação e cidadania em São Paulo. São Paulo: Ed. 34/Edusp, 2000.

CARDIA, N.; ADORNO, S.; POLETO, F. Homicídio e violação de direitos humanos em São Paulo. Estud. Av., v.17, n.47, p.43-73, 2003.

CASTEL, R. De la peligrosidad al riesgo. In: ALVAREZ-URÍA, F.; VARELA, J. (Eds.). Materiales de sociología crítica. Madrid: La Piqueta, 1986. p.219-43.

CZERESNIA, D. Ciência, técnica e cultura: relações entre risco e práticas de saúde. Cad. Saude Publica, v.20, n.2, p.447-55, 2004.

DELOR, F; HUBERT, M. Revisiting the concept of 'vulnerability'. Soc. Sci. Med., v.50, n.11, p.1557-70, 2000.

FELTRAN, G.S. Trabalhadores e bandidos: categorias de nomeação, significados políticos. Temáticas, v.15, n.30, p.11-50, 2007.

GAWRYSZEWSKI, V.P.; COSTA, L.S. Homicídios e desigualdades sociais no município de São Paulo. Rev. Saude Publica, v.39, n.2, p.191-7, 2005.

GIDDENS, A. Modernidade e identidade. Rio de Janeiro: Jorge Zahar, 2002.

KRUG, E.G. et al. (Eds.). Relatório mundial sobre violência e saúde. Genebra: Organização Mundial da Saúde, 2002.

LA MENDOLA, S. O sentido do risco. Tempo Soc., v.17, n.2, p.59-91, 2005.

LE BRETON, D. Passions du risque. Paris: Éditions Métailié, 2000.

LUPTON, D. Risk. London: Routledge, 1999.

MANNHEIM, K. O problema sociológico das gerações. In: FORACCHI, M.M. (Org.). Coleção grandes cientistas sociais. São Paulo: Ática, 1982. p.67-95.

MELLO-JORGE, M.H.P. Adolescentes e jovens como vítimas da violência fatal em São Paulo. In: PINHEIRO, P.S. et al. (Orgs.). São Paulo sem medo: um diagnóstico da violência urbana. Rio de Janeiro: Garamond, 1998. p. 97-120.

MINAYO, M.C.S. A violência na adolescência: um problema de saúde pública. Cad. Saude Publica, v.6, n.3, p.278-92, 1990.

MINAYO, M.C.S.; SOUZA, E.R. Violência e saúde como um campo interdisciplinar e de ação coletiva. Hist. Cienc. Saude-Manguinhos, v.4, n.3, p.513-31, 1997. 
MITJAVILA, M.R.; JESUS, C.S. Globalização, modernidade e individualização social. Rev. Katálysis, v.7, n.1, p.69-79, 2004.

PAIS, J.M. Ganchos, tachos e biscates: jovens, trabalho e futuro. Porto: Ambar, 2005.

PAULILO, M.A.S.; BELLO, M.G.D. Jovens no contexto contemporâneo: vulnerabilidade, risco e violência. Ser. Soc. Rev., v.4, n.2, 2002. Disponível em: <http://www.ssrevista. uel.br/>. Acesso em: 22 jan. 2010.

PERALVA, A. Violência e democracia: o paradoxo brasileiro. São Paulo: Paz e Terra, 2000.

PERES, M.F.T. Homicídios, risco e vulnerabilidade: para uma discussão da dinâmica da vitimização por homicídios. In: CRUZ, M.V.G.; BATITUCCI, E.C. (Orgs.). Homicídios no Brasil. Rio de Janeiro: Ed. FGV, 2007. p.125-39.

SANCHEZ, A.I.M.; BERTOLOZZI, M.R. Pode o conceito de vulnerabilidade apoiar a construção do conhecimento em Saúde Coletiva? Cienc. Saude Colet., v.12, n.2, p.319-24, 2007.

SCHRAIBER, L.B.; GOMES, R.; COUTO, M.T. Homens e saúde na pauta da saúde coletiva. Cienc. Saude Colet., v.10, n.1, p.7-17, 2005.

SECRETARIA MUNICIPAL DE SAÚDE. PRO-AIM. Programa de aprimoramento das informações de mortalidade. Disponível em: <http://portal.prefeitura.sp.gov.br/ secretarias/saude/tabnet>. Acesso em: 6 jan. 2010.

SENNET, R. A corrosão do caráter: conseqüências pessoais do trabalho no novo capitalismo. Rio de Janeiro: Record, 2005.

SOUZA, E.R. Masculinidade e violência no Brasil: contribuições para a reflexão no campo da saúde. Cienc. Saude Colet., v.10, n.1, p.59-70, 2005.

SOUZA, E.R.; LIMA, M.L.C. The panorama of urban violence in Brazil and its capitals. Cienc. Saude Colet., v.11, n.2, p.363-73, 2006.

TELLES, V.S. Mutações do trabalho e experiência urbana. Tempo Soc., v.18, n.1, p.173-95, 2006.

ZALUAR, A. A integração perversa: pobreza e tráfico de drogas. Rio de Janeiro: Ed. FGV, 2004.

O condomínio do diabo. Rio de Janeiro: Ed. UFRJ, 1994.

RUOTTI, C.; MASSA, V.C.; PERES, M.F.T. De la vulnerabilidad y la violencia: una nueva concepción del riesgo para el estudio de homicidios de jóvenes. Interface - Comunic., Saude, Educ., v.15, n.37, p.377-89, abr./jun. 2011.

En el campo de la salud pública la violencia ha sido estudiada en consonancia con la clásica perspectiva de riesgo. Los análisis dentro de esa perspectiva permiten evidenciar las tendencias de morbidez y mortalidad en la población e identificar los factores del riesgo. Sin embargo, aunque importantes como fuentes de informaciones e hipótesis, estos análisis aislados no son capaces de explicar la complejidad del fenómeno. Este artículo tiene como objetivo iniciar una reflexión sobre el uso del concepto de vulnerabilidad en el estudio de la violencia, específicamente en el entendimiento de las situaciones que colocan a los jóvenes como principales víctimas de homicidios. Así, se propone una nueva concepción del riesgo teniendo en cuenta los procesos sociales y culturales presentes en la vulnerabilidad de ese grupo a la violencia letal, usando una perspectiva que presente las especificidades de la condición juvenil y los desafíos representados por la conformación social contemporánea.

Palabras clave: Riesgo. Vulnerabilidad. Homicidios. Jóvenes.

Recebido em 09/04/2010. Aprovado em 28/09/2010 
